\title{
RESERVOIR EFFECT OF ARCHAEOLOGICAL SAMPLES FROM STEPPE BRONZE AGE CULTURES IN SOUTHERN RUSSIA
}

\begin{abstract}
N Shishlina ${ }^{1} \cdot$ V Sevastyanov $^{2} \cdot$ E Zazovskaya $^{3} \cdot \mathrm{J}_{\text {van der Plicht }}{ }^{4}$
ABSTRACT. Human and animal bone collagen from different Steppe Bronze Age cultures, including the Yamnaya, East Manych Catacomb, and Lola cultures, show large variations in $\delta^{13} \mathrm{C}$ and $\delta^{15} \mathrm{~N}$ values. More positive values of $\delta^{13} \mathrm{C}$ and $\delta^{15} \mathrm{~N}$ are caused by change in diet and/or a more arid climate. Human bones show reservoir effects caused by aquatic diet components. These effects can be quantified by paired dating of human bone and associated terrestrial samples. Previous research showed reservoir corrections for several cultures of the Eurasian steppes Bronze Age, leading to a revision of the local chronologies. Additional investigations showed that some paired dates do not reveal reservoir effects. Recently, our database was extended significantly with new ${ }^{13} \mathrm{C},{ }^{15} \mathrm{~N}$, and ${ }^{14} \mathrm{C}$ analyses of the Lola, Krivaya, and Babino cultures. The size of the reservoir offset for the studied cultures is discussed.
\end{abstract}

\section{INTRODUCTION}

For Bronze Age Eurasian steppe graves, paired radiocarbon dating of samples from the contemporaneous archaeological context enabled the identification of variations in reservoir effects obtained for several cultures (Shishlina et al. 2007, 2009). We studied populations that exploited the area between the Lower Don and the Lower Volga rivers and the North Caucasus piedmont. The exploitation of this new area was based on a multicomponent mobile economy, including (1) raising of domesticated animals (sheep/goat, cattle, and probably horse); (2) seasonal movements across vast areas, including the coastlines of the Black and Azov seas; (3) fishing and gathering of wild plants; and (4) a system of exchange. The values of $\delta^{13} \mathrm{C}$ and $\delta^{15} \mathrm{~N}$ for human bones show different diet systems, which were reconstructed for various population groups (Shishlina et al. 2012b). Humans are at the end of the trophic chain and, as consumers, are representatives of a mixed and multicomponent diet system. In addition, previously obtained strontium data indicate that at least some of the individuals probably moved from one place to another quite regularly since their childhood and consumed food, which causes different isotope signals (Shishlina and Larionova, in press).

The consumption of aquatic food components, including freshwater and marine food, causes apparent ${ }^{14} \mathrm{C}$ ages of dated human bones. We performed analysis of ${ }^{13} \mathrm{C},{ }^{15} \mathrm{~N}$, and ${ }^{14} \mathrm{C}$ isotopes from collagen extracted from human and animal bones, including paired dating of human bones and terrestrial samples. In previous publications, several regional offsets were suggested based on the first measurements of the ${ }^{14} \mathrm{C}$ age of paired terrestrial and human bone samples as well as terrestrial and aquatic samples (Shishlina et al. 2007, 2009). A reservoir offset of 400-500 yr was derived for the Early Catacomb culture, and 300-450 yr for the East Manych Catacomb culture. However, the more paired samples analyzed, the more complicated the situation became.

Our hypothesis is that different components of the human diet are reflected in different reservoir correction values. If the human diet contained different amounts of aquatic resources with different ${ }^{14} \mathrm{C}$ ages, the reservoir effect signals would be different due to geological factors as well as ecological and economic contexts of each culture. The southern part of Russia, i.e. the Caspian and Lower Don areas, are investigated during 5000-2000 cal BC.

1. State Historical Museum, Moscow, Russia. Corresponding author. Email: nshislina@mail.ru.

2. Institute of Geochemistry and Analytical Chemistry, Russian Academy of Sciences, Moscow, Russia.

3. Institute of Geography, Russian Academy of Sciences, Moscow, Russia.

4. Centre for Isotope Research, Groningen University, Groningen, the Netherlands; also at Faculty of Archaeology, Leiden University, Leiden, the Netherlands.

Proceedings of the Radiocarbon and Archaeology 7th International Symposium

Ghent, Belgium, April 2013 | Edited by Mark Van Strydonck, Philippe Crombé, and Guy De Mulder

(C) 2014 by the Arizona Board of Regents on behalf of the University of Arizona 
The aim of the present article is to analyze paired ${ }^{14} \mathrm{C}$ dates obtained for different population groups and discuss the following issues:

(i) The variations in reservoir effect offsets obtained for several cultures, which occupied the same area under different ecological conditions and exploited different food resources; and

(ii) A possible correlation between human stable isotopes and reservoir effect offsets.

\section{MATERIALS AND METHODS}

This study used data from several archaeological cultures, i.e. the Eneolithic, Majkop, Yamnaya, Steppe North Caucasus, Early Catacomb, Eastern Manych, and Lola cultures. Their time intervals and regional distributions are shown in Table 1 and Figure 1, respectively. Archaeological human and animal bone samples were subjected to analysis. Some data were published previously (Shishlina at al. 2007, 2009, 2012b). New samples of human and animal bones as well as wood and plants coming from excavations near the village of Remontnoye in the Rostov region (southern Russia) where ${ }^{14} \mathrm{C}$ dates and additional stable isotope ratios were measured.

Most stable isotope ratio measurements were made in the Institute of Geochemistry and Analytical Chemistry, the Russian Academy of Sciences, using the isotope mass-spectrometer DELTA Plus XP (ThermoFinnigan), linked to a Flash EA element analyzer. Each sample was measured in triplicate with an analytical error for $\delta^{13} \mathrm{C}$ of $\pm 0.2 \%$ and for $\delta^{15} \mathrm{~N}$ of $\pm 0.2-0.3 \%$. A subset of the measurements was made at Groningen University. After the chemical pretreatment, the prepared collagen is combusted and turned into $\mathrm{CO}_{2}$ by an elemental analyzer (EA), coupled on-line with a stable isotope mass spectrometer (MS). The EA is also used for purifying the $\mathrm{CO}_{2}$ (Aerts-Bijma et al. 2001). In addition, the EA/MS system enables precise measurement of the $\delta^{13} \mathrm{C}$ values.

Table 1 Analyzed cultures and their chronologies.

\begin{tabular}{ll}
\hline Culture & Time interval \\
\hline Eneolithic & $4300-3800 \mathrm{cal} \mathrm{BC}$ \\
Yamnaya & $3000-2500 \mathrm{cal} \mathrm{BC}$ \\
Early Catacomb & $2700-2400 \mathrm{cal} \mathrm{BC}$ \\
North Caucasus & $2600-2400 \mathrm{cal} \mathrm{BC}$ \\
East Manych Catacomb & $2500-2200 \mathrm{cal} \mathrm{BC}$ \\
Lola, Early Babino, Krivaya Luka & $2200-1900 \mathrm{cal} \mathrm{BC}$ \\
\hline
\end{tabular}

For ${ }^{14} \mathrm{C}$, the $\mathrm{CO}_{2}$ is subsequently reduced to graphite by reacting under excess $\mathrm{H}_{2}$ gas. This graphite is pressed into target holders that are placed in the ion source of the accelerator mass spectrometry (AMS). The Groningen AMS facility is based on a 2.5MV accelerator (van der Plicht et al. 2000). For fossil bones, established quality parameters are the organic carbon and nitrogen content of the collagen, which should be within specified ranges (DeNiro 1985). For our samples, these parameters are good to reasonable.

The isotope ratios are reported in per mil deviation with respect to the international standards VPDB and AIR for ${ }^{13} \mathrm{C}$ and ${ }^{15} \mathrm{~N}$, respectively. Conventional ${ }^{14} \mathrm{C}$ dates were measured at the Institute of Geography of the Russian Academy of Sciences using liquid scintillation (lab code IGAN). AMS dates were obtained at Groningen University (lab code GrA). For bone samples, collagen was extracted using an improved version of the Longin (1971) method. The ${ }^{14} \mathrm{C}$ dates are reported in conventional yr BP. They are calibrated into calendar years (cal BC) using the calibration curve IntCal09 (Reimer et al. 2009). 


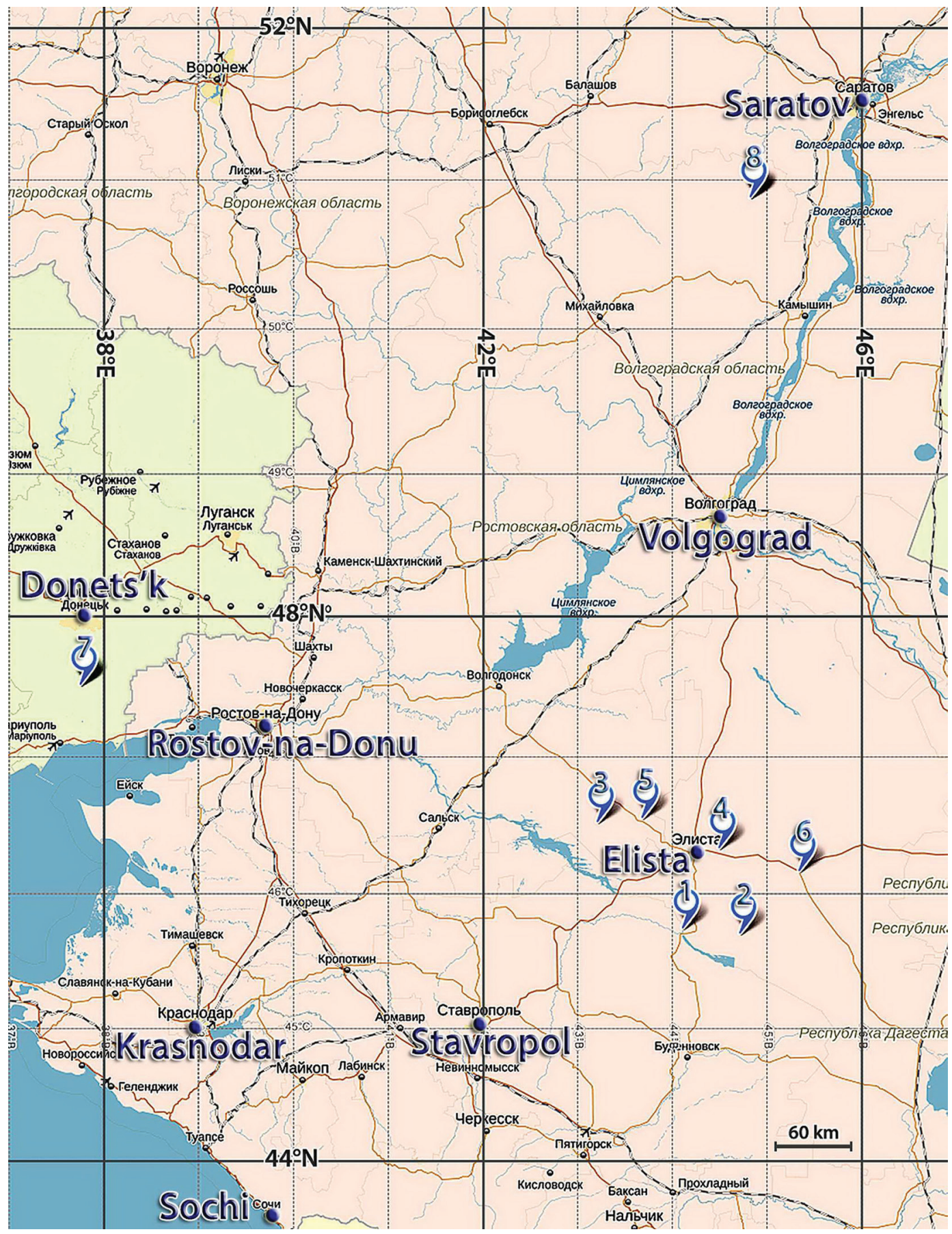

Figure 1 Location of the Lola, Early Babino and Krivaya Luka sites: 1 - Ostrovnoy, 2 - Mandjikiny-1, 3 - Temrta 1, 4 - Khar-Zukha, 5 - Peschany V, 6 - Yashkul 1, 7 - Khomush-Oba, 8 - Linevo. 


\section{RESULTS AND DISCUSSION}

We performed ${ }^{14} \mathrm{C}$ dating of 47 paired samples, including pairs of both terrestrial samples (woodplant; wood-animal bone; animal bone-plant) and terrestrial and aquatic samples (shell-plant; fish bone-plant). Forty such pairs result from ${ }^{14} \mathrm{C}$ dates of human bone and associated terrestrial samples (animal bone, wood, and plant). The results are discussed below for the various cultures (Figure 3).

\section{Eneolithic Culture}

Only one pair of dates is presently available, i.e. cow and human bones from the Eneolithic Khvalynsk Cemetery II, grave 10 . The offset is $220{ }^{14} \mathrm{C}$ yr. We assume that other ${ }^{14} \mathrm{C}$ dates of human bones available for this culture also would show this apparent age. The average value of the $\delta^{15} \mathrm{~N}$ ratio in human bone collagen from the Khvalynsk humans is $+13 \%$ (Shishlina et al. 2012a). This provides the size of the reservoir effect correction (Shishlina et al. 2009). People belonging to this culture consumed quite a lot of aquatic food. Stable isotope data available for five human bones confirm this statement (Shishlina 2008).

The consumption of freshwater fish by the local Eneolithic population of the adjacent Dnieper Basin in Ukraine also causes apparent ages of dated humans from the Molukhov Bugor burial ground. The reservoir effect correction for this case is $110{ }^{14} \mathrm{C}$ yr (Lillie et al. 2009).

\section{Majkop Culture}

Unfortunately, our database does not contain paired dates for the Majkop culture thus far, despite the fact that the both human and terrestrial samples obtained from different Majkop graves were ${ }^{14} \mathrm{C}$ dated. Human bones of the same cultural context are sometimes older than ${ }^{14} \mathrm{C}$ dates of terrestrial samples. Terrestrial samples (pairs such as plant textile-animal bone) dating from the same grave do not show any offset (Shishlina 2008: Table 11). Stable isotope values obtained for steppe Majkop bones (Shishlina et al. 2012b: Table 4) show that an aquatic component in the diet of this population is likely. Without paired ${ }^{14} \mathrm{C}$ dates from the same Majkop grave context, we can only speculate that ${ }^{14} \mathrm{C}$ dates obtained from humans might be older than ${ }^{14} \mathrm{C}$ dates of terrestrial samples (animal bones, textile plant fibers). Due to the average value of the $\delta^{15} \mathrm{~N}$ in Majkop human bone collagen (human $=7$ ), which is $+14 \%$, we estimate that the reservoir effect can be up to several hundred years. Future paired dating will clarify this hypothesis.

Hollund et al. (2010) analyzed four pairs obtained from Aygurskiy Majkop culture graves (human and animal bones, including snake bones). The results yield paired dates without a significant reservoir age in three cases, and with a reservoir effect in one pair (from 315 to $172 \mathrm{yr}$, grave 8) (Hollund et al. 2010: Table 3).

\section{Yamnaya Culture}

There are eight paired dates available for this local culture including dates of humans of different age and sex, domesticated animals, bone items made of ungulate bone, and wood samples. In addition, one pair of human and ungulate bone of the Repino culture is available. ${ }^{1}$ In four cases, human bones show reservoir effects, caused by aquatic diet components.

Four out of the eight paired cases do not show any age offset. This can be explained in two alternative ways. One is that the human diet did not include aquatic components; rather, the diet was based on $\mathrm{C}_{3}$ vegetation with high $\delta^{15} \mathrm{~N}$ values (13-15\%), and flesh/milk of domesticated animals. 
An alternative explanation is that humans consumed food from freshwater resources without a reservoir effect. The isotope composition of the local plants and domesticated animal bones indicates that in some cases, due to the arid conditions of the environment, plants show elevated $\delta^{15} \mathrm{~N}$ values. Therefore, the local population as well as domesticated animals feeding on these plants also show high $\delta^{15} \mathrm{~N}$ values (Shishlina et al. 2012a,b).

Reservoir effect corrections for other dated pairs vary between 200 and $270 \mathrm{yr}$ (Shishlina et al. 2009, 2012 b). The new pair from Peschany V, kurgan 15, grave 6 (human bone and wood) shows a very large reservoir effect of $860 \mathrm{yr}$ for the human bone collagen. This large effect dates back to around $3000 \mathrm{BC}$ when people started to occupy different pastures located across the exploited area.

\section{Catacomb Cultures (Early Catacomb, West and East Manych Catacomb Cultures)}

A lot of isotopic data are available for this period (Shishlina at al. 2012b). They clearly show the role of aquatic food components in the diet of the local steppe population. This is confirmed by fish bones and scales identified in the graves, as well as by impressions of nets on the bottom of some clay pots (Shishlina 2008). The size of the reservoir effect varies from 100 to $750 \mathrm{yr}$. Isotope data for dated human bones also show large variations. We assume that some individuals consumed fish obtained from different reservoirs, determined by their seasonal movements. People were very mobile at that time (Shishlina 2008) and during their seasonal movements, probably consumed aquatic food with different isotope values and ${ }^{14} \mathrm{C}$ ages. This leads to apparent ages in the ${ }^{14} \mathrm{C}$ dates of human bones.

There are four pairs without offsets in the Catacomb culture database, though the isotope values of such pairs are similar to those of humans who fed on fish (Shishlina et al. 2012a). A similar situation is observed for the North Caucasus Piedmont steppes (Hollund et al. 2010). Humans from the Ipatovo burial ground, kurgan 2, in the Stavropol region show a very small reservoir effect or no reservoir effect at all.

\section{Lola, Babino, and Krivaya Luka Cultures}

New stable isotope and ${ }^{14} \mathrm{C}$ data are available for these cultures and are shown in Table 2 and Figure 3. The stable isotope values for human bones vary significantly; the diet of the people of these cultures does not correspond to the steppe diet of the local population, the value for which is -22.2 to $-17.5 \%$ for $\delta^{13} \mathrm{C}$, and +9.4 to $+17.1 \%$ for $\delta^{15} \mathrm{~N}$ (Shishlina et al. 2012a). We assume that the isotope ecology of the Caspian and Lower Don steppe areas changed during a period of aridization, which reached its peak in 2200-2000 cal BC (Borisov and Mimokhod 2011). Another possible explanation is that some individuals from those cultures came to this part of the steppe from the regions where food components show different isotope signals. Besides that, the ${ }^{87} \mathrm{Sr} /{ }^{86} \mathrm{Sr}$ values obtained for enamel of some individuals (Shishlina and Larionova, in press) indicate that some of these humans were not local, so they consumed food produced in different areas. This is reflected in specific isotope values in their bone collagen, which differ from the values for the local steppe population.

Fifteen ${ }^{14} \mathrm{C}$ dates are available for these three cultures; 8 human bones, 6 animal bones, and 1 wood sample were ${ }^{14} \mathrm{C}$ dated. They are listed in Table 3 . 
Table 2 Stable isotope data for humans and animals from Lola, Krivaya Luka, and Babino cultures.

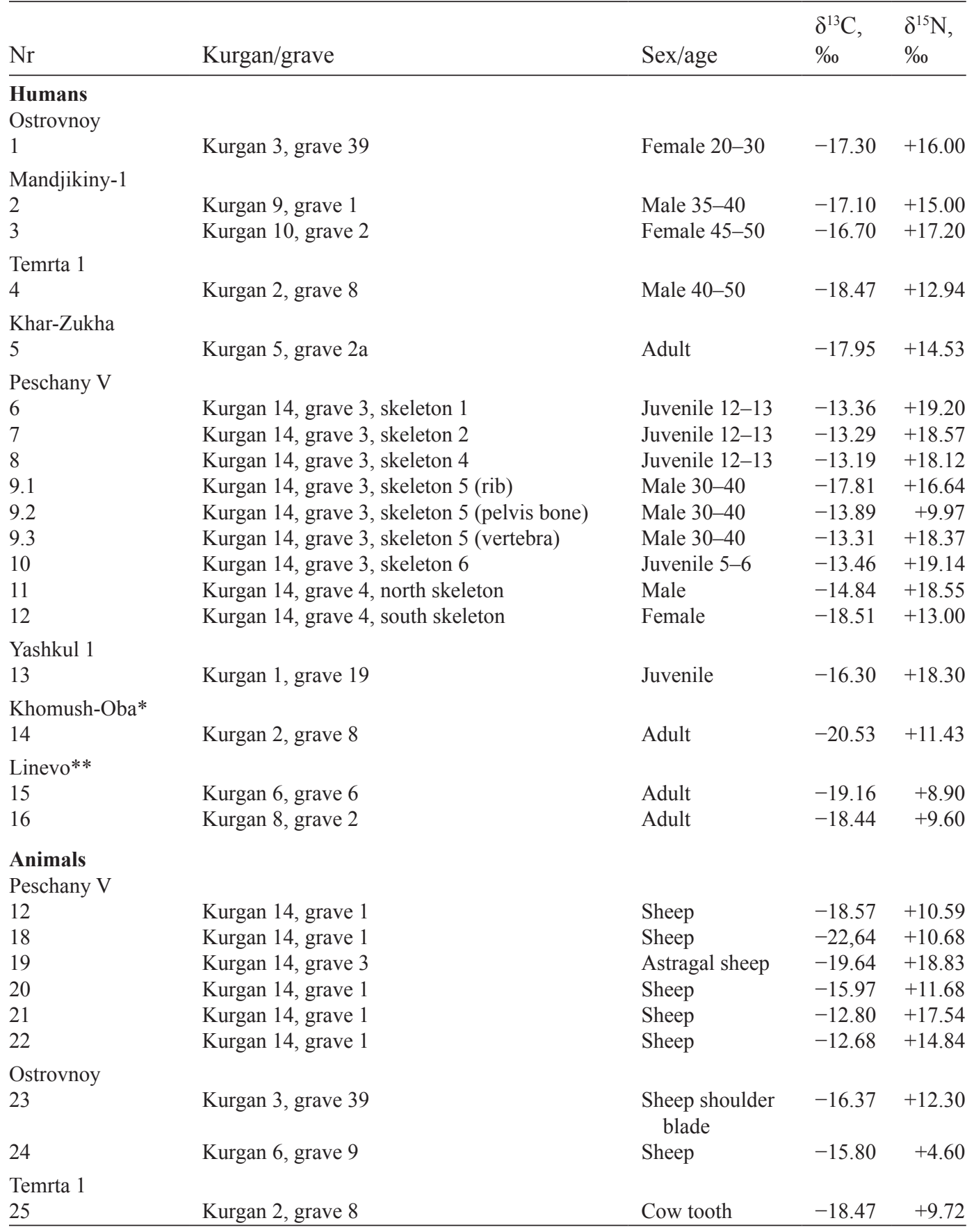

*Early Babino culture.

**Krivaya Luka cultural group. 


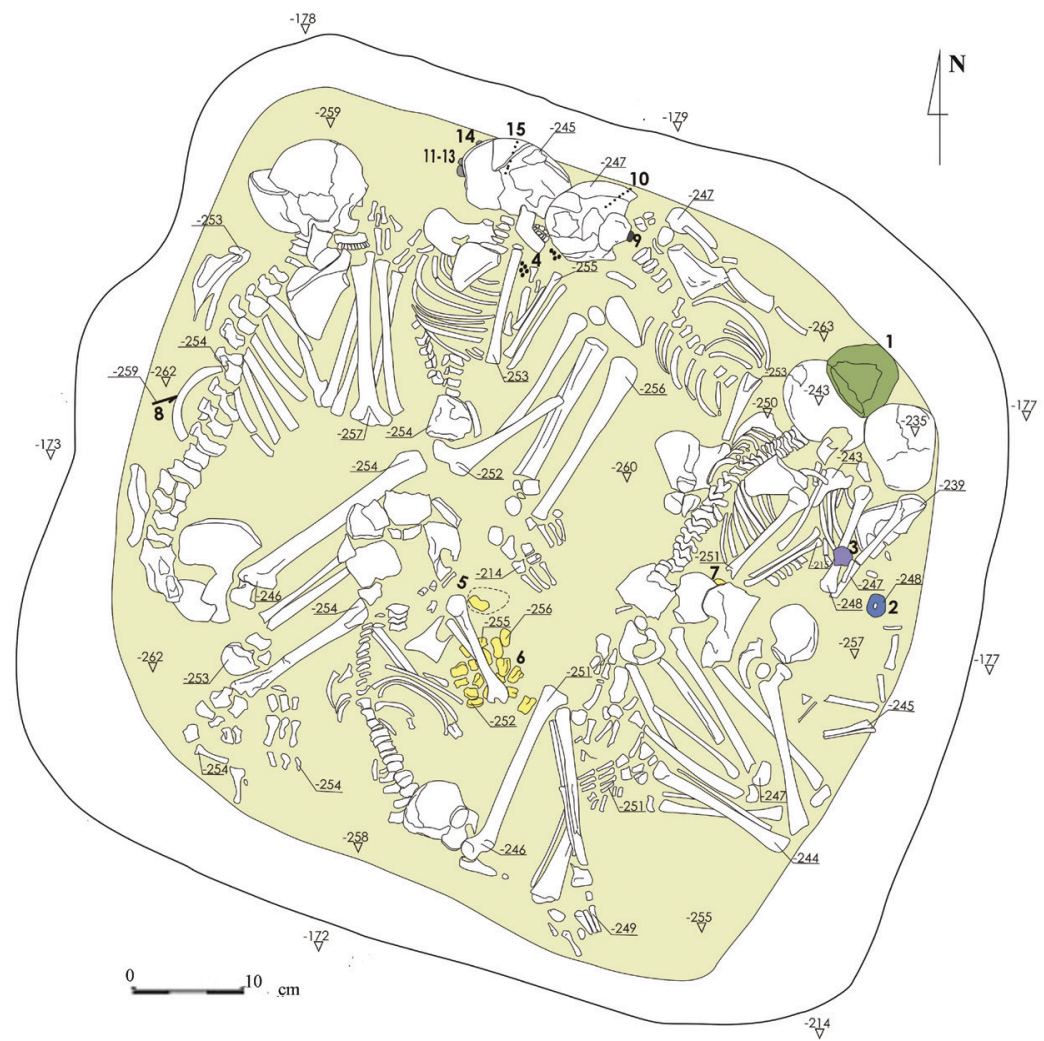

Figure 2 Peschany V, kurgan 14, grave 3: 1 - clay pot; 2 - spindle whorl, 3 - shell, 4 - beads, 5 - astragal, 6 - group of astragals, 7 - astragal, 8 - bone arrow head, 9-15 bone items.

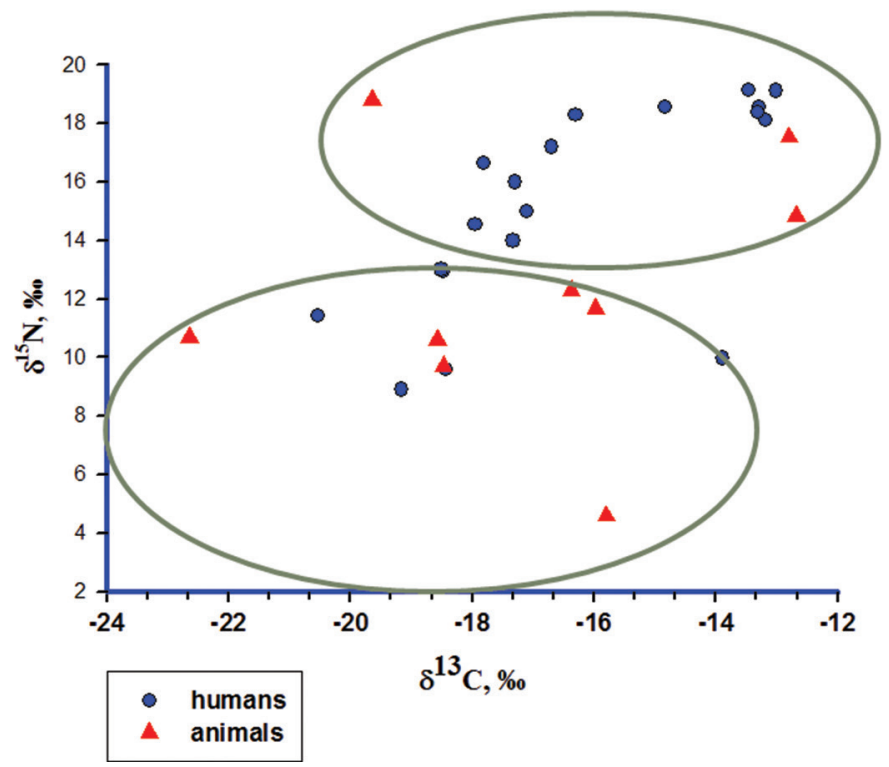

Figure 3 Plot for isotope data presented in Table 2 
Some human bones from the dated pairs do not show a reservoir effect (from Temrta and Khomush Oba). Others do show offsets, which vary between 114 and $185 \mathrm{yr}$. We assume that the offset of $1084 \mathrm{yr}$ calculated for the first pair from Ostrovnoy, kurgan 39, grave 3, is not correct. The reason for this unrealistic value needs to be further investigated. The second pair from this grave shows a reservoir effect of $114 \mathrm{yr}$ for the human bone.

The Peschany kurgan 14, grave 3 (Figure 2), located in the Rostov region is an interesting case. Six juveniles and one adult male were buried in one grave at the same time. One animal bone (sheep astragals) and three humans (juveniles \#1 and 4, and the adult male) were dated (Table 3, Figure 3). For five humans and six associated animal bones, stable isotope measurements are available as well (Table 2). As is shown for the Peschany case, there is no correlation between the value of the reservoir effect correction and the isotope values $\left({ }^{13} \mathrm{C}\right.$ and $\left.{ }^{15} \mathrm{~N}\right)$ for the dated humans. In such cases, stable isotope values cannot be used to determine the size of the reservoir effect correction as was done for other regions (Wood et al. 2013).

Figure 4 shows the variations in reservoir effects for the cultures discussed. Though the stable isotope values calculated for three dated humans are similar, the reservoir effect of $185 \mathrm{yr}$ for juvenile \#4 indicates that aquatic components were predominant in the diet of this individual. Another juvenile (\#1) and an adult male consumed terrestrial food, which shows isotope values similar to those of fish and water plants. It might have been caused by aridization, which changes the isotope values of local plant samples (Shishlina et al. 2012a), or a different place of origin of the Lola population. The human-animal pair from Aygurskiy burial 1 from the Stavropol region, which dates back to the same period, does not show any reservoir effect either (Hollund et al. 2010).

\section{Concluding Remarks}

A multicomponent human diet causes different reservoir effect value corrections obtained for the Eurasian and North Caucasus adjacent steppe areas. This is illustrated in Figure 4. Despite that, for some periods, such as the Eneolithic and the Steppe Majkop culture, there are insufficient data. We may assume that the Caspian and Lower Don Steppe areas demonstrate a very interesting case for studies of the reservoir effect correction.

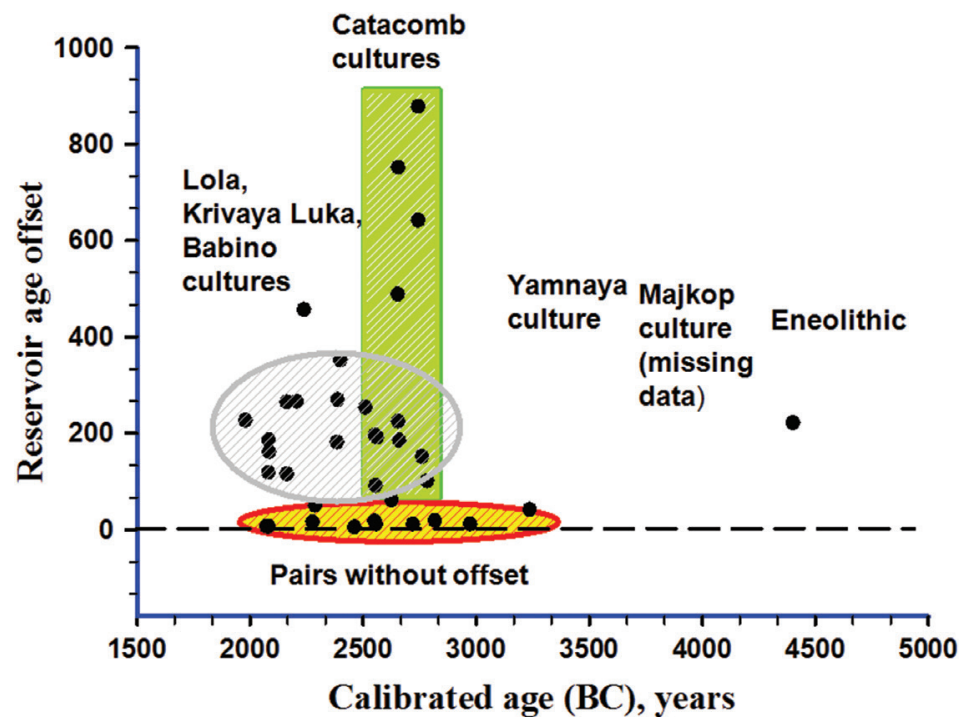

Figure 4 Variations in reservoir effect correction for the cultures under discussion 
Reservoir Effect of Archaeological Samples from Steppe Bronze Age

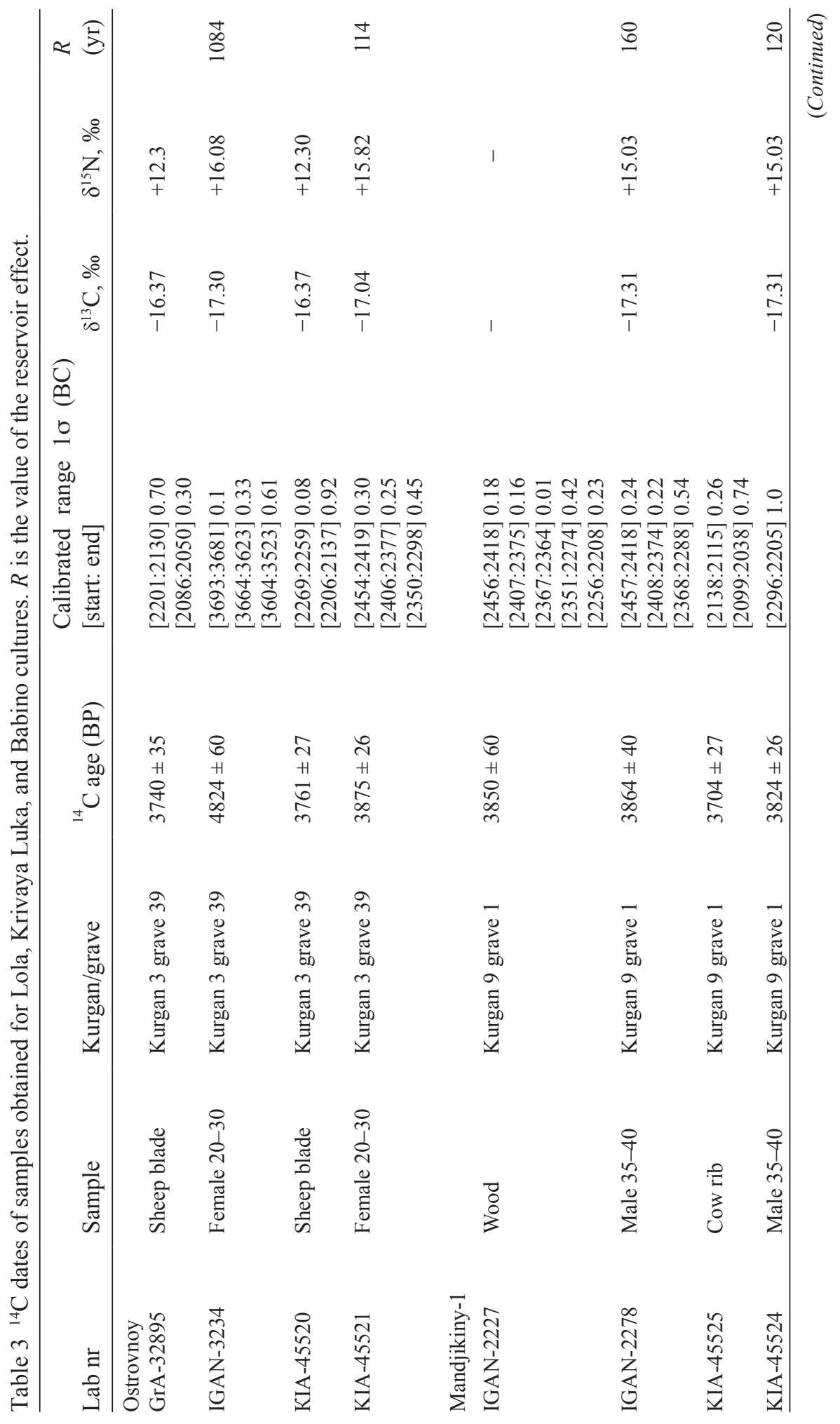




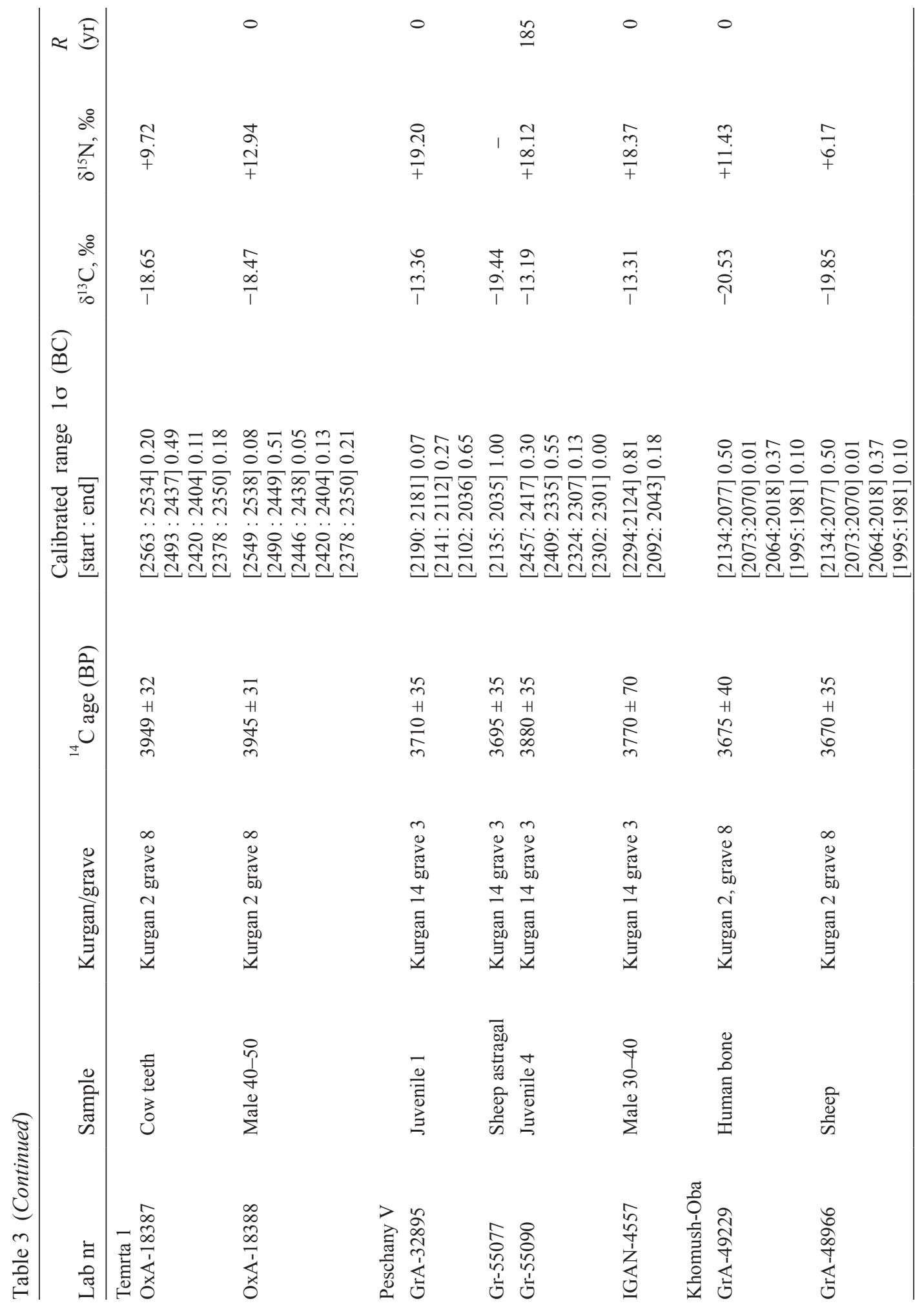


At the end of the 4th millennium BC, people began to move deeper into the steppe and as they expanded, they exploited the area (Shishlina 2008). Their diet became more varied because they raised cattle for exchange rather than for domestic consumption. Hence, they were forced to use whatever was available in any form. The easiest way was to include aquatic resources into everyday diet. An abundance of small steppe rivers and lakes as well as large tributaries and rivers, such as the Don or the Volga, were used for drinking water for the animals. Usually, animals were brought to the watering place at least twice a day (Shishlina 1997). It was easy to obtain some aquatic food including fish, edible mollusks, as well as water plants for animals during such visits. We also assume that steppe people consumed fish from different reservoirs with different isotopic history and signals.

The consumption of aquatic components results in an increased ${ }^{14} \mathrm{C}$ age of human bone collagen. The ${ }^{14} \mathrm{C}$ age of archaeological and contemporaneous fish from the area analyzed (Shishlina et al. 2009) shows that the age of fish varies and might yield an age up to $1000 \mathrm{yr}$ older than that of contemporaneous terrestrial samples. The same situation is observed for other regions as well (Lanting and van der Plicht 1998; Wood et al. 2013). Mobility caused people to consume aquatic food with different isotope values. The reservoir effect correction calculated for the period dating back to the end of the 4th millennium BC and the first half of the 3rd millennium BC varies from 0 to $850 \mathrm{yr}$.

As is clear from Figure 4, it becomes obvious that many steppe people consumed fish. However, other studies show that some individuals (including Majkop and Catacomb cases in the Stavropol region) did not consume fish at all (Hollund et al. 2010). In the subsequent period, human activities changed. Aridization occurred during the second half of the 3rd millennium BC (Borisov and Mimokhod 2011), causing rivers and lakes to become dry and causing fish to become a product in short supply. People shifted to a diet containing significantly less fish, which is confirmed by the data shown in Figure 2. Many reservoir effect values are less than 100 yr. The same has been observed by Hollund at al. (2010) in the Stavropol region. The value of this reservoir effect appears to vary due to climate change and changes in diet.

The derived variations in reservoir effect corrections among the humans who might belong to the same group (like the Peschany case) from 0 to 185 yr show that sometimes there is no correlation between the values of the reservoir effect correction and the stable isotope values.

\section{ACKNOWLEDGMENTS}

This work was supported by RFFI grant nr13-06-12003.

\section{REFERENCES}

Aerts-Bijma AT, van der Plicht J, Meijer HAJ. 2001. Automatic AMS sample combustion and $\mathrm{CO}_{2}$ collection. Radiocarbon 43(2A):293-8.

Borisov AV, Mimokhod RA. 2011. The role of the environment in the origin of the Lola culture. In: Makarov NA, Nosov EN, editors. Papers of the III (XIX) Russian Congress of Archaeologists. Volume 2. Novgorod: IIMK-IA RAS. p 370-1.

DeNiro MJ. 1985. Postmortem preservation and alteration of in vivo bone collagen isotope ratios in relation to palaeodietary reconstruction. Nature 317(6040):806-9.

Hollund HI, Higham T, Belinskij A, Korenevskij S. 2010. Investigation of palaeodiet in the North Caucasus (South Russia) Bronze Age using stable isotope analysis and AMS dating of human and animal bones. Journal of Archaeological Science 37(12):2971-83.

Lanting JN, van der Plicht J. 1998. Reservoir effects and apparent ${ }^{14} \mathrm{C}$-ages. The Journal of Irish Archaeology IX:151-65.

Lillie M, Budd C, Potekhina I, Hedges R. 2009. The radiocarbon reservoir effect: new evidence from the cemeteries of the middle and lower Dnieper basin, Ukraine. Journal of Archeological Science 36(2):256-64.

Longin R. 1971. New method of collagen extraction for radiocarbon dating. Nature 230(5291):241-2.

Reimer PJ, Baillie MGL, Bard E, Bayliss A, Beck JW, Blackwell PG, Bronk Ramsey C, Buck CE, Burr GS, Edwards RL, Friedrich M, Grootes PM, Guilderson TP, Hajdas I, Heaton TJ, Hogg AG, Hughen 
KA, Kaiser KF, Kromer B, McCormac FG, Manning SW, Reimer RW, Richards DA, Southon JR, Talamo S, Turney CSM, van der Plicht J, Weyhenmeyer CE. 2009. IntCal09 and Marine09 radiocarbon age calibration curves, $0-50,000$ years cal BP. Radiocarbon 51(4):1111-50.

Shishlina NI. 1997. Review of the herding economy in modern Republic of Kalmykia. Steppe and the Caucasus (cultural traditions). In: Kozhin P, editor. Papers of the State Historical Museum. Volume 97. Moscow: State Historical Museum. p 106-9.

Shishlina NI. 2008. Reconstruction of the Bronze Age of the Caspian Steppes. Life Styles and Life Ways of Pastoral Nomads. BAR International Series 1876. Oxford: Archaeopress.

Shishlina NI, van der Plicht J, Hedges REM, Zazovskaya EP, Sevastianov VS, Chichagova OA. 2007. The Catacomb cultures of the North-west Caspian steppe: ${ }^{14} \mathrm{C}$ chronology, reservoir effect, and paleodiet. Radiocarbon 49(2):713-26.

Shishlina NI, Zazovskaya EP, van der Plicht J, Hedges REM, Sevastyanov VS, Chichagova OA. 2009. Paleoecology, subsistence, and ${ }^{14} \mathrm{C}$ chronology of the Eurasian Caspian steppe Bronze Age. Radiocarbon 51(2):481-99.

Shishlina NI, Sevastyanov V, Hedges R. 2012a. Isotope ratio study of Bronze Age samples from the Eurasian Caspian steppes. In: E Kaiser, I Burger, W
Schier, editors. Population Dynamics in Prehistory and Early History. New Approaches Using Stable Isotopes and Genetics: Berlin: Walter de Gruyter. p 177-97.

Shishlina NI, Zazovskaya E, van der Plicht J, Sevastyanov V. 2012b. Isotopes, plants, and reservoir effects: case study from the Caspian Steppe Bronze Age. Radiocarbon 54(3-4):749-60.

Shishlina NI, Larionova YuO. In press. Pastoral exploitation of the Caspian and Don steppes and the North Caucasus during the Bronze Age: seasonality and isotopes. In: Collins J, editor. Malga, Buron, Alm, Shieling, Seter, Salaš, Orry and Cayolar: Seasonal Exploitation of Uplands from Prehistory to the Modern Day. London: Oxbook.

Trifonov VA. 1996. Repino Culture and the Origin of the Yamnya Culture. Ancient Cultures of the Volga-Don Steppes in the Eastern Europe Bronze Age System. Volgograd: Peremena. p 3-5.

van der Plicht J, Wijma S, Aerts AT, Pertuisot MH, Meijer HAJ. 2000. Status report: the Groningen AMS facility. Nuclear Instruments and Methods in Physics Research B 172(1-4):58-65.

Wood RE, Higham TFG, Buzilhova A, Suvorov A, Heinemeier J, Olsen J. 2013. Freshwater radiocarbon reservoir effects at the burial ground of Minino, northwest Russia. Radiocarbon 55(1):163-77. 